\title{
Comparison of the Amplitudes of the H-reflex of Post-stroke Hemiplegia Patients and Normal Adults during Walking
}

\author{
Sung-Hyoun Cho, MS, PT ${ }^{1)}$, Jung-Ho Lee, MS, PT ${ }^{1 * *}$ \\ 1) Department of Physical Therapy, Graduate School of Physical Therapy, Daegu University: Naeri-ri, \\ Jinlyang, Gyeongsan-si, Kyeongsangbuk-do 15, Republic of Korea. TEL: +82 10-2934-5433
}

\begin{abstract}
Purpose] The purpose of this study was to compare H-reflex characteristics during gait of hemiplegic stroke patients. [Subjects] Twenty-five patients and age-matched twenty-five volunteers in good health were studied. All the subjects could walk independently. [Methods] An MP150 (BIOPAC Systems, Inc., Goleta, CA, USA) was used to record the electromyography (EMG) data collected with $\mathrm{Ag}-\mathrm{Ag} / \mathrm{Cl}$ measurement electrodes (BIOPAC, diameter of $2 \mathrm{~cm}$ ). [Results] The comparison showed significant differences of $\mathrm{H}_{\max } / \mathrm{M}_{\max }$ ratio (\%) in all gait cycles between the stroke group and the control group. [Conclusion] In conclusion, this study furnished basic reference data for gait strategies and functional training programs for hemiplegic stroke patients.

Key words: H-reflex, Gait, Hemiplegia
\end{abstract}

(This article was submitted Jan. 9, 2013, and was accepted Feb. 15, 2013)

\section{INTRODUCTION}

Hemiplegic stroke patients are restricted in their daily life due to lowered exercise ability, weakened muscular strength, and muscle stiffening ${ }^{1)}$. Generally, about 50 to $80 \%$ of stroke survivors acquire the ability to maintain balance three weeks after the occurrence of the stroke or after leaving the hospital, and once motility is secured, they become capable of walking ${ }^{2)}$.

However, many patients still have disorders such as a slower walking pace or reduced endurance, and are restricted in their independent mobility at home or in the workplace $^{3)}$. Therefore, the recovery of walking ability becomes an important goal in the rehabilitation of stroke patients ${ }^{4)}$.

The distinctive walking patterns of stroke patients include a slow gait cycle and walking speed, time asymmetry between the leg on the affected side and the leg on the unaffected side, and a relatively short stance phase on the affected side and a long swing phase ${ }^{5)}$. In addition, stroke patients lack the ability to generate voluntary muscle contraction to a normal extent and cannot generate the proper timing and intensity of muscle activities ${ }^{2}$. The focus of the rehabilitation of stroke patients is to increase their balance ability and generate proper functional movements ${ }^{6}$. Therefore, in order to evaluate functional losses or treatment results and project prognoses, an objective and quantitative evaluation of hemiplegic patients is required. The quantitative evaluations used in the clinical setting are the Ashworth scale ${ }^{7)}$, the pendulum test ${ }^{8)}$, and an electrodiagnostic method using the H-reflex ${ }^{9}$.

${ }^{*}$ To whom correspondence should be addressed.

E-mail: 1jhcivapt@naver.com
The spinal cord motor reflex examined by the electrically stimulated H-reflex plays an important role in posture control. The H-reflex controls posture in the performance of different postural tasks, movements requiring high levels of changes, and activities involving changes in postural angle ${ }^{10)}$.

It is essential to find out the accurate causes and body areas of abnormality in patients with pathologic gait, and compare and evaluate the findings through the process of objectifying and quantifying. The abnormal gaits of hemiplegic patients have been a topic of continuous research, and many recent studies have carried out gait analyses based on electromyography $(\mathrm{EMG})^{11,12)}$. However, EMG-based studies about the H-reflex of hemiplegic stroke patients and normal adults during the gait cycle still remain inadequate.

The purpose of this study was to examine the effects of the H-reflex on the soleus muscle of hemiplegic stroke patients and normal adults during walking and on their gait cycle, to furnish basic data for diagnosis and adjustment of the control of abnormal muscles in hemiplegic stroke patients.

\section{SUBJECTS AND METHODS}

\section{Subjects}

The subjects of this study were normal adults $(n=25)$, and patients who were diagnosed with hemiplegia resulting from a stroke $(n=25)$. Our experiment was conducted after explaining the purpose of this study to the subjects and gaining their consent. The normal group consisted of 15 women and 10 men with an age range of 58 to 75 who had no orthopedic diseases that could affect their gait or balance. The patient group consisted of patients who had hemiplegia due to cerebral infarction or hemorrhage and were being 
treated at Hospital B in Ulsan. The patient group consisted of 18 men and seven women with Brunnstrom stages ranging from three to five. The average duration since stroke onset in the patient group was $20.88 \pm 8.35$ months. Five patients had hemiplegia on the right side, and 20 patients had it on the left side. The averages of NIHSS (National Institutes of Health Stroke Scale) and Brunnstrom stage of the patient group were $9.08 \pm 2.57$ score and $3.88 \pm 0.78$ respectively. The patients could walk independently over $10 \mathrm{~m}$ indoors without a walking aid and were capable of performing the experiment according to the experimenter's requests (Table 1$)$

\section{Methods}

To record and process EMG measurements a MP150 (BIOPAC System Inc., Goleta, CA, USA) was used with $\mathrm{Ag}-\mathrm{Ag} / \mathrm{Cl}$ (BIOPAC, diameter $2 \mathrm{~cm}$ ) electrodes. The EMG signals were collected using a sampling rate of $1000 \mathrm{~Hz}$, and processed by full-wave rectification. While the subjects were walking, data was collected using Acknowledge 4.1 (BIOPAC System Inc., Goleta, CA, USA) software. In order to measure the H-reflex, data were band-pass filtered between 30 to $500 \mathrm{~Hz}$, and for the removal of noise, the signals were processed by notch-filtering at $60 \mathrm{~Hz}$.

In order to measure the H-reflex, a line was drawn between the center of the folds of the popliteal fossa and the medial malleolus of each subject, and a recording electrode was attached to the inner muscle belly of the soleus muscle, which lay at the midpoint of the line. In addition, a standard electrode was attached to the distal part, $15 \mathrm{~cm}$ from the achilles tendon. The stimulating electrode used in this experiment was a bipolar electrode. It was attached to the popliteal fossa with its cathode positioned on the proximal part so that it would stimulate the tibial nerve. For the ground electrode, a $1 \times 1 \mathrm{~cm}$ self-adhesive disposable electrode (Neuroline Disposable Neurology Electrodes 700 10-k, Medicotest A/S, Olstykke, Denmark) was attached between the stimulating and recording electrodes. The electric stimulation was delivered to the center of the folds of the hamstring muscle to the posterior tibial nerve using the bipolar electrode at the level of submaximal stimulation at intervals of two seconds. The H-reflex was elicited by low voltage with duration of a current about $1 \mathrm{msec}$ and at a rate of once every $2 \mathrm{sec}$ to prevent the direct stimulation of motor neuron axons and the generation of M-waves. In an EMG analysis, the effective blocking of noise is of the utmost importance; there, we paid careful attention to the

Table 1. General characteristics of subjects $(\mathrm{M} \pm \mathrm{SD})$

\begin{tabular}{lcc}
\hline & Normal $(\mathrm{n}=25)$ & Stroke $(\mathrm{n}=25)$ \\
\hline Age $(\mathrm{yrs})$ & $65.52 \pm 10.63$ & $67.56 \pm 11.25$ \\
Height $(\mathrm{cm})$ & $165.44 \pm 9.36$ & $167.84 \pm 9.56$ \\
Weight $(\mathrm{kg})$ & $65.84 \pm 11.02$ & $72.72 \pm 9.86$ \\
Leg length $(\mathrm{cm})$ & $80.64 \pm 4.36$ & $87.76 \pm 5.21$ \\
\hline
\end{tabular}

$\mathrm{M} \pm \mathrm{SD}:$ Mean \pm standard deviation

Leg length is the length from the anterior-superior spine of the ilium to the medial malleolus. selection of electrode locations. Moreover, in order to prevent noise from the connecting leads, the leads were firmly fixed with tape.

Each subject was instructed to walk on a treadmill comfortably while wearing EMG pads, and the experiment began when the subject exhibited his/her natural gait. The experiment was carried out while the subject did not feel fatigued by having to pay attention and concentrate. While the subject was walking, stimuli were delivered to elicit the H-reflex in the four gait phases of heel-strike, mid-stance, toe-off, and mid-swing. The stimuli for the H-reflex were manually delivered as a square voltage pulse of 0.1 seconds in the four gait phases, and the timing of the stimulation was displayed on a screen. The amplitude of the H-reflex and the amplitude of the M-wave were measured, and the amplitude was measured as peak-to-peak values. After checking for the presence of the $\mathrm{H}$-wave, the stimulus strength was slowly adjusted to find $\mathrm{H}_{\max }$ and $\mathrm{M}_{\max }$, and the $\mathrm{H}_{\max } / \mathrm{M}_{\max }$ ratio was calculated as the maximum amplitude ratio of the two action potentials ${ }^{13}$. The research results were statistically analyzed using SPSS version 12.0 (ICC, Chicago, IL, USA). The physical characteristics of each group, and the measurement data of each variable are presented as the average and standard deviation which were calculated using descriptive statistics. In order to compare the H-reflexes of the patient group and the normal group, the independent ttest was performed. Statistical significance was accepted for values of $\mathrm{p}<0.05$.

\section{RESULTS}

The H-reflex amplitudes of the hemiplegic patients were $28.41 \pm 7.46 \%$ in the swing phase, $28.22 \pm 7.75 \%$ in the heelstrike phase, $46.15 \pm 15.43 \%$ in the mid-stance phase, and $36.19 \pm 15.20 \%$ in the toe-off phase. Those of the normal adults were $8.82 \pm 2.49 \%$ in the swing phase, $12.68 \pm 4.29 \%$ in the heel-strike phase, $34.62 \pm 13.31 \%$ in the mid-stance phase, and $7.52 \pm 1.69 \%$ in the toe-off phase (Table 2). Additionally, according to the independent t-test, statistically significant differences were present in all the phases, with values of $p=0.000$ in the swing phase, $p=0.00$ in the heelstrike phase, $p=0.004$ in the mid-stance phase, and $p=0.00$ in the toe-off phase $(\mathrm{p}<0.01)$.

Table 2. The H-reflex amplitudes of the stroke group and the normal group during walking (unit: \%)

\begin{tabular}{lcccc}
\hline & Group & N & M \pm SD & \\
\hline \multirow{2}{*}{ Swing phase } & Stroke & 25 & $28.41 \pm 7.46$ & $* * *$ \\
& Normal & 25 & $8.82 \pm 2.49$ & \\
Heel strike & Stroke & 25 & $28.22 \pm 7.75$ & $* * *$ \\
& Normal & 25 & $12.68 \pm 4.29$ & \\
Mid-stance & Stroke & 25 & $46.15 \pm 15.43$ & $* *$ \\
& Normal & 25 & $34.62 \pm 13.31$ & \\
Toe-off & Stroke & 25 & $36.19 \pm 15.20$ & $* * *$ \\
& Normal & 25 & $7.52 \pm 1.69$ & \\
\hline
\end{tabular}

$\mathrm{M} \pm \mathrm{SD}:$ Mean \pm standard deviation

$* \mathrm{p}<0.05, * *: \mathrm{p}<0.01, * * *: \mathrm{p}<0.001$ 


\section{DISCUSSION}

When treating hemiplegic stroke patients, improving walking ability is very important, as walking is an essential element for gaining functional independence in stroke patients' daily lives ${ }^{14)}$. In order to improve walking ability, the studies of normal gait, which provide gait standards for patients, are necessary. Moreover, analyses of the causes of abnormal gait patterns exhibited by patients and the objective assessments of their treatment results are also important.

The H-reflex is a single synapse reflex conducted by the central nervous system and provides information that is functionally important to peripheral sensory and motor nerves ${ }^{15}$. The H-reflex is a single synapse reflex that is used to evaluate functional conditions of the spinal reflex loop and has been employed in the evaluation of spinal excitability. Particularly, H-reflex research has focused on its relation with the various disease conditions that lower the excitability of spinal motor neurons ${ }^{16,17}$.

The H-reflex amplitude shows wide variations with change in stimulus and is highly affected by the central nervous system. It is also heavily influenced by subjects' gait, degree of tension release, intensity and duration of electrostimulation, location of electrodes, age, and body temperature $^{18)}$. Therefore, the H-reflex is known to vary widely not only between individuals, but also within the same individual $^{19}$ ). Such a phenomenon occurs due to the existence of many factors that can affect the $\alpha$-motor neuron and changes in the excitability of the synapse in the central nervous system between the Ia afferent nerve and the motor neuron in the muscle spindles ${ }^{19}$ ). Therefore, measurement of spinal neuron excitability change is possible by measuring the amplitude of the $\mathrm{H}$-wave, and calculating the $\mathrm{H}_{\max } / \mathrm{M}_{\max }$ ratio is the commonly used method of $\mathrm{H}$-reflex normalization $^{20)}$. The $\mathrm{H}_{\max } / \mathrm{M}_{\max }$ ratio can be said to be an accurate index that shows the frequency and amount of excitatory alpha motor neurons according to the activity of descending tract $^{13)}$. In the present study, we measured the maximum amplitudes of the $\mathrm{H}$-wave and the $\mathrm{M}$-wave to compare $\mathrm{H}_{\max }$ amplitude to $\mathrm{M}_{\max }$ amplitude ratios.

In a study that examined the H-reflex amplitudes during walking at a speed of $1.2 \mathrm{~km} / \mathrm{h}$ by two age groups of 7 to 14 and 13 to 16 , the highest amplitude was reported to have occurred in the mid-stance phase, which follows the heel-strike phase, whereas the toe-off, swing, and heelstrike phases were observed to have similar amplitudes ${ }^{21)}$. A similar result was also reported in a gait analysis of normal adults aged 20 to 40 in another study ${ }^{22)}$.

In contrast, people with upper motor neuron syndrome (UMNS), such as stroke patients, are reported to have a gait pattern of abnormal muscle activation in their lower limb muscles ${ }^{23)}$. The reason for this is that, the dorsiflexion of the ankles is disturbed at the initial activity during the stance phase because their calf muscles are stretched ${ }^{24)}$.

According to the results of this study, the H-reflex amplitude of the hemiplegic stroke patients was at its highest in the mid-stance phase and at its lowest in the heel-strike phase. In the normal adults, the H-reflex amplitude was the highest in the mid-stance phase and the lowest in the toe-off phase. In both the hemiplegic stroke patients and the normal adults, the highest amplitude of the H-reflex was detected in the mid-stance phase, a result which is a similar to those of previous studies. However, unlike in the normal group, the lowest amplitude in the patient group was during the heelstrike phase ${ }^{25}$. Additionally, in all the phases of the gait cycle, the H-reflex amplitude exhibited a statistically significant difference between the patient and normal groups. We attribute this to the nature of the disease, as hemiplegic stroke patients tend to show a gait pattern of stiff walking due to muscle spasticity, which is accompanied by a tendency toward circumduction or dragging of the feet. Moreover, hemiplegic stroke patients with neurologic lesions have difficulties generating appropriate levels of muscle contraction and control.

This study demonstrated that statistically significant differences exist in the amplitudes of the H-reflex during the gait cycle between hemiplegic stroke patients and normal adults. This study investigated the H-reflexes during walking of hemiplegic stroke patients and normal adults. We hope the data of this report will contribute to the provision of effective gait strategies and functional training programs for hemiplegic stroke patients in the future.

\section{REFERENCES}

1) Bourbonnais D, Vanden Noven S, Carey KM, et al.: Abnormal spatial patterns of elbow muscle activation in hemiparetic human subjects. Brain, 1989, 112: 85-102. [Medline] [CrossRef]

2) Olney SJ, Richards C: Hemiparetic gait following stroke, part I. characteristics. Gait Posture, 1996, 4: 136-148. [CrossRef]

3) Chen R, Gosavi NS, Langston JW, et al.: Parkin mutations are rare in patients with young-onset parkinsonism in a US population. Parkinsonism Relat Disord, 2003, 9: 309-312. [Medline] [CrossRef]

4) Werner C, Von Frankenberg S, Treig TK, et al.: Treadmill training with partial body weight support and an electromechanical gait trainer for restoration of gait in subacute stroke patients: a randomized crossover study. Stroke, 2002, 33: 2895-2901. [Medline] [CrossRef]

5) Mauritz KH: Gait training in hemiplegia. Eur J Neurol, 2002, 9: 23-29. [Medline] [CrossRef]

6) Walker C, Brouwer BJ, Culham EG: Use of visual feedback in retraining balance following acute stroke. Phys Ther, 2000, 80: 886-895. [Medline]

7) Blackburn M, van Vliet P, Mockett SP: Reliability of measurements obtained with the modified ashworth scale in the lower extremities of people with stroke. Phys Ther, 2002, 82: 25-34. [Medline]

8) Bohannon RW, Larkin PA: Lower extremity weight bearing under various standing conditions in independently ambulatory patients with hemiparesis. Phys Ther, 1985, 65: 1323-1325. [Medline]

9) Levin MF, Hui-Chan $\mathrm{CW}$ : Are $\mathrm{H}$ and stretch reflexes in hemiparesis reproducible and correlated with spasticity? J Neurol, 1993, 240: 63-71. [Medline] [CrossRef]

10) Koceja DM, Trimble MH, Earles DR: Inhibition of the soleus H-reflex in standing man. Brain Res, 1993, 629: 155-158. [Medline] [CrossRef]

11) Ivanenko YP, Popple RE, Lacquaniti F: Five basic muscle activation patterns account for muscle activity during human locomotion. J Physiol, 2004, 556: 267-282. [Medline] [CrossRef]

12) Saunders SW, Rath D, Hodges PW: Postural and respiratory activation of the trunk muscles changes with mode and speed of locomotion. Gait Posture, 2004, 20: 280-290. [Medline] [CrossRef]

13) Pensini M, Martin A: Effect of voluntary contraction intensity on the $\mathrm{H}-$ reflex and V-wave response. Neurosci Lett, 2004, 367: 369-374. [Medline] [CrossRef]

14) Davies P: Steps to follow. A guide to the treatment of adult hemiplegia. Berlin: Springer-Verlag, 2000, pp 15-20.

15) Cliffer KD, Tonra JR, Carson SR, et al.: Consistent repeated M-and Hwave recording in the hind limb of rats. Muscle Nerve, 1998, 21: 14051413. [Medline] [CrossRef]

16) Jaberzadeh $S$, Scutter $S$, Warden-Flood A, et al.: Between-days reliability 
of H-reflexs in human flexor carpi radialis. Arch Phys Med Rehabil, 2004, 85: 1168-1173. [Medline] [CrossRef]

17) Sugawara K, Kasai T: Facilitation of motor evoked potentials and H-reflex of flexor carpi radialis muscle induced by voluntary teeth clenching. Hum Mov Sci, 2002, 21: 203-212. [Medline] [CrossRef]

18) Nishida T, Kompoliti A, Janssen I, et al.: H reflex in S1 radiculopathy, Latency versus amplitude controversy revisited. Muscle Nerve, 1996, 19 915-917. [Medline] [CrossRef]

19) Garrett $M$, Caulfield $B$ : Increased $H_{\max }: M_{\max }$ ratio in community walkers poststroke without increase in ankle plantarflexion during walking. Arch Phys Med Rehabil, 2001, 82: 1066-1072. [Medline] [CrossRef]

20) Palmieri RM, Ingersoll CD, Hoffman MA: The Hoffmann reflex: meth odologic considerations and applications for use in sports medicine and athletic training research. J Athl Train, 2004, 39: 268-277. [Medline]
21) Hodapp M, Klisch C, Berger W, et al.: Modulation of soleus H-reflexes during gait in healthy children. Exp Brain Res, 2007, 178: 252-260. [Medline] [CrossRef]

22) Krauss EM, Misiaszek JE: Phase-specific modulation of the soleus Hreflex as a function of threat to stability during walking. Exp Brain Res, 2007, 181: 665-672. [Medline] [CrossRef]

23) Knutsson E, Richards C: Different types of disturbed motor control in gait of hemiparetic patients. Brain, 1979, 102: 405-430. [Medline] [CrossRef]

24) Orendurff MS, Segal AD, Aiona MD, et al.: Triceps surae force, length and velocity during walking. Gait Posture, 2005, 21: 157-163. [Medline] [CrossRef]

25) Simonsen EB, Dyhre-Poulsen P, Alkjaer T, et al.: Interindividual differences in $\mathrm{H}$ reflex modulation during normal walking. Exp Brain Res, 2002, 142: 108-115. [Medline] [CrossRef] 